\title{
WESTERN BLOT PARA O DIAGNÓSTICO DAS INFECÇÕES PELOS LENTIVÍRUS DE PEQUENOS RUMINANTES EM CAPRINOS: UM MÉTODO SIMPLES PARA A PRODUÇÃO DE ANTÍGENO
}

\author{
M.M.M. Oliveira ${ }^{1}$, M.A. de Melo라 , P.P. de Andrade ${ }^{3}$, S.M. Gomes ${ }^{1 *}$, \\ A.C. Campos ${ }^{1}$, S.A. do Nascimento ${ }^{1}$, R.S. de Castro ${ }^{1}$
}

${ }^{1}$ Universidade Federal Rural de Pernambuco, Departamento de Medicina Veterinária, Laboratório de Viroses dos Animais Domésticos, Av. Dom Manoel de Medeiros s/no, CEP 52171-900, Recife, PE, Brasil. E-mail: michelemoreira2005@gmail.com

\section{RESUMO}

O sorodiagnóstico das lentiviroses de caprinos e ovinos é realizado principalmente pela imunodifusão em gel de agar (AGID) e/ ou ELISA. Embora relativamente simples, esses métodos não identificam os antígenos virais reconhecidos na resposta imune do animal examinado, por isso o western blot (WB) vem ganhando maior relevância como ferramenta de diagnóstico dessas enfermidades. Neste trabalho, o antígeno utilizado no WB foi obtido através de um sistema simplificado de purificação: concentração por diálise do sobrenadante de culturas celulares infectadas, seguido de centrifugação em gradiente contínuo de sacarose. A separação das proteínas virais foi obtida por SDS-PAGE a $10 \%$ e a transferência para membranas de nitrocelulose realizada pelo sistema semi-úmido. A revelação das membranas mostrou reconhecimento pelo soro padrão positivo de cinco proteínas, com pesos moleculares de 14-16, 25, 40,50 e 70 kDa. Todas as 8 amostras de soro caprino, positivas na ADIG, reconheceram pelo menos uma banda proteíca noimmunoblot, variando contudo o número de bandas reconhecidas. Reação positiva à glícoproteína 40 (gp 40) foi observada em quatro animais, com intensidade de reação discreta em três deles. Dois animais apresentaram reação positiva à proteína 16 (p16), e dois à gp 50, de pouca intensidade. Quanto à gp 70, proteína que, embora reagisse com o soro padrão positivo, não foi reconhecida por nenhum dos soros testados. Estes resultados sugerem que oWB pode ser empregado para o sorodiagnóstico rotineiro das lentiviroses, ensejando estudos mais amplos do padrão de reconhecimento dos antígenos apresentados por este novo sistema de purificação parcial de componentes virais.

PALAVRAS-CHAVE: Enfermidade, diagnóstico, CAEV, células, córnea, purificação, SDS-PAGE, immunoblot.

\section{ABSTRACT}

WESTERN BLOT FOR THE DIAGNOSIS OF SMALL RUMINANT LENTIVIRUS INFECTIONS IN GOATS: A SIMPLE METHOD FOR ANTIGEN PRODUCTION. The serodiagnosis of small ruminant lentivirus (SRLV) infections in goats and sheep is usually performed by the agar-gel immunodiffusion technique (AGID) and by ELISA. Therefore, the western blot (WB) is the choice for the definition of antigen recognition patterns during the disease progression, being potentially useful for the diagnosis itself. In the present study, the antigen used for WB was obtained by a novel simple purification procedure: the dialysis of the supernatant of infected cultured cells, followed by centrifugation in sucrose gradient. Proteins in the pellet were separated by SDS-PAGE at 10\% density and transferred to nitrocellulose membranes in a semi-dry blotting device. After development, five viral proteins were recognized by the standard positive serum sample, with molecular weights of 14-16, 25, 40, 50 and $70 \mathrm{kDa}$ respectively. All 8 AGID positive goat serum samples recognized at least one band in the immunoblot, with different intensities. The total number of bands recognized by each serum sample varied considerably. A positive reaction to gp40 was observed with 4 sera, although rather weak in 3 cases. Two samples were reactive to p16

\footnotetext{
${ }^{2}$ Universidade Federal de Campina Grande, Centro de Saúde e Tecnologia Rural, Unidade Acadêmica de Medicina Veterinária, Patos, PB, Brasil.

${ }^{3}$ Universidade Federal de Pernambuco, Departamento de Genética, Recife, PE, Brasil.

*Mestranda do Programa de Pós-graduação em Ciência Veterinária - UFRPE.
} 
and two others to gp50, although weakly. Curiously, no serum was reactive to the $70 \mathrm{kDa}$ antigen, recognized by the standard positive serum sample. These results suggest that the WB can be effectively used for the routine serodiagnosis of viral caprine arthritis encephalitis infection $(\mathrm{CAEV})$. It can also support further studies on antigen recognition patterns with the new antigen provided by the novel simplified purification system of viral components described here.

KEY WORDS: Cells, corneal, purification, SDS-PAGE, immunoblot.

\section{INTRODUÇÃO}

Os Lentivírus de pequenos ruminantes (SRLV) são agrupados em cinco grupos filogenéticos, representados por dois grupos mais importantes que contemplam os protótipos dos vírus da artrite-encefalite caprina (CAEV) e de Maedi-Visna (MVV) (SHAH et al., 2004). Estes vírus causam infecção caracterizada, muitas vezes, por animais soropositivos aparentemente saudáveis. Entretanto, apenas aproximadamente $25 \%$ dos caprinos e ovinos infectados com SRLV podem desenvolver artrite, sobretudo na articulação carpo-metacarpiana, encefalomielites, emagrecimento, mastite e pneumonia progressiva (CALLADO et al., 2001). Não existe tratamento para as SRLV nem vacinas eficazes. Por isso o diagnóstico é uma ferramenta essencial para o seu controle.

No Brasil, o Plano Nacional de Vigilância e Controle de Lentiviroses de Pequenos Ruminantes (PNVCLVPR), que integra o Programa Nacional de Sanidade dos Caprinos e Ovinos (PNSCO) do Ministério da Agricultura, Pecuária e Abastecimento (MAPA) (BRASIL, 2004), em fase de estruturação, preconiza o uso da imunodifusão em gel de agar (AGID) como teste diagnóstico para LVPR. Porém, existe a carência de um teste que seja tido como padrão ouro, em nível nacional, este testeé owesternblot(WB)citado por alguns autores (ZANONI et al., 1989; HUUWERS; NaUta, 1989; KajIKAWA et al., 1990).

OWB tem sido utilizado comumente como padrão ouro (gold standard), em padronizações e validações de muitos testes de ELISA para diagnóstico de SRLV em ovinos (ZANONi et al., 1989) e também como ferramenta na análise da resposta imunológica de ovinos natural e experimentalmente infectados com MaediVisna (Houwers; NAuta, 1989; KajiKaWa et al., 1990). Porém, relatos sobre sua aplicação na espécie caprina são escassos, sendo descrito apenas um WB usando antígeno recombinante (RosATi et al., 1995).

No desenvolvimento de um teste sorológico, o processo de produção e purificação do antígeno empregado é um passo importante (CeLER; CeleR, 2001). Muitos protocolos para produção e purificação de antígeno com fins diagnósticos para SRLV têm sido estabelecidos e empregam, de forma simples ou combinada, as seguintes técnicas: centrifugação simples, centrifugação e/ou ultracentifugação em gradiente contínuo ou descontínuo de sacarose, filtração pressurizada, cromatografias de troca-iônica e de afinidade, concentração e precipitação com polietilenoglicol 8.000 (PEG 8.000) (SIMARD et al.,2001; ZANON et al., 1994; SIMARD; BRISCOE, 1990a; SiMARD; BRISCOE, 1990b; ARCHAMBault et al., 1988; HouwERs et al., 1982). A maioria destes é laboriosa e demorada, pois contemplam várias etapas de processamento, requerendo uma estrutura laboratorial sofisticada.

Este trabalho teve como objetivo propor um protocolo simples de obtenção de antígeno e a padronização preliminar de um western blot (WB) para diagnóstico de SRLV em caprinos.

\section{MATERIAL E MÉTODOS}

\section{Cultivo celular e infecção in vitro}

Foram cultivadas células epiteliais de córnea de feto caprino, provenientes de mães soronegativas, obtidas por explantação. Os explantes de córnea embebidosem meioessencial mínimo deEagle(MEM), suplementado com antibióticos (penicilina e estreptomicina) e antifúngicos (fungizon ou anfotericina B) foram transferidos para garrafas plásticas de cultivo celular de $25 \mathrm{~cm}^{2}$, incubados a $37^{\circ} \mathrm{C}$ por 30 minutos. Em seguida, foram adicionados $5 \mathrm{~mL}$ de MEM suplementado com $10 \%$ de soro fetal bovino (SFB), seguindo-se o cultivo a $37^{\circ} \mathrm{C}$, em atmosfera de $5 \%$ de $\mathrm{CO}_{2}$, até total confluência da monocamada celular. As culturas estabelecidas foram adaptadas para o cultivo em garrafas roller.

As monocamadas celulares subconfluentes, cultivadas em garrafas roller, que se encontravam na $10^{a}$ passagem, foram infectadas com amostra viral CAEV Cork ${ }^{a}$ (NARAYAN et al., 1980). A partir do $10^{\circ}$ dia pós-inoculação, a cada três dias, o sobrenadante (sbn) de cada garrafa era coletado e congelado, acrescentando-se às garrafas $200 \mathrm{~mL}$ de MEM com $2 \%$ de SFB. As garrafas eram substituídas quando

aAmostras gentilmente cedidas pelo Laboratoire d'Immunologie et de Biologie Pulmonaire (INSERM-Hôpital Louis Pradel de Lyon-France) e Laboratoire Associé de Recherches sur les Lentivirus chez les Petits Ruminants (INRA-Ecole National Vétérinaire de Lyon-France). 
apresentavam mais de $80 \%$ de destruição da monocamada celular.

\section{Produção e avaliação dos antígenos}

Para produção dos antígenos, os sbn foram congelados e descongelados três vezes, clarificados por centrifugação (3.300 g por 20 minutos, a $4^{\circ} \mathrm{C}$ ) e dialisados contra PEG 8.000 a 40\% em PBS (pH 7,6), a $4^{\circ} \mathrm{C}$ durante 48 a 72 horas, até a concentração de aproximada de 50 vezes (CALLADO, 1999), seguido de centrifugação em gradiente contínuo de sacarose (25\%) em solução tampão TRIS - Cloreto de sódio EDTA (TNE), a $21.460 \mathrm{~g}$ por 2 horas e meia, a $4^{\circ} \mathrm{C}$. O pellet foi ressuspenso em dodecil sulfato de sódio a $0,25 \%$. Células não infectadas foram submetidas a este mesmo protocolo e utilizadas como controle negativo do antígeno no dot-blot e no WB.

Para determinar a concentração de proteínas foi utilizada a técnica descrita por Bradford, modificada por SEDMAK; GROSSBERG (1977), utilizando como padrão a albumina sérica bovina (BSA), nas concentraçãoes de $0,1,20,30,40,50,60,70,80$, 90 e $100 \mu \mathrm{g} / \mathrm{mL}$.

A avaliação do antígeno purificado foi realizada através do WB, padronizado a partir do dot-blot. Para tal, foram empregadas fitas nitrocelulose de $6 \mathrm{~mm} \times 6$ $\mathrm{cm}$ (de largura e comprimento, respectivamante) com porosidade de $0,45 \mu \mathrm{m}$. Nestas, foram distribuídos $4,8 \times 10^{-4} \mu \mathrm{g} / \mu \mathrm{L}$ da proteína antigênica purificada, em diluições duplas de 1/2 a 1/64, bem como o controle do antígeno, para determinar a diluição de uso. Após secagem, por 20 minutos, em temperatura ambiente, as fitas foram lavadas três vezes, por cinco minutos, sob leve agitação, com solução de lavagem TBST 0,1\% (100 mM de TRIS-HCl; pH8,0; 150 mM de NaCl, 0,1\% de Tween 20) e bloqueadas com solução de bloqueio (TBST 0,1\%, 1\% de leite em pó desnatado [LPD]) (CELER et al., 1998), por uma hora, sob leve agitação, a temperatura de $25-27^{\circ} \mathrm{C}$. O soro padrão positivo, de um kit comercial ${ }^{\mathrm{b}}$, e o negativo, de um animal com resultado negativo em três testes consecutivos de ADIG, utilizandokitcomercial,já citado anteriormente,foram diluídos (1/10a1/1.600) em solução diluente do soro (TBST 0,1\%,1\% de LPD, $10 \mathrm{mM}$ de EDTA e $\%$ de SFB), incubados a $37^{\circ} \mathrm{C}$, por uma hora; distribuídos, eas fitas incubadas como descrito anteriormente. O conjugado anti-cabra peroxidase utilizado no dotblot e no WB foi produzido de acordo com CASTRO (1998). Este foi diluído em solução do conjugado (TBST 0,1\%,1\% de LPD), de 1/100 a 1/800, distribuído, e as fitas incubadas a temperatura ambiente, sob leve agitação, por uma hora. Posteriormente, foram lavadas cinco vezes por cinco minutos, e o substrato $3^{\prime}-3^{\prime}-5^{\prime}-5^{\prime}$ - Tetrametilbenzidina (TMB), na concentração de $2,4 \times 10^{-3} \mathrm{~g} / \mathrm{mL}$, foi adicionado. A reação foi interrompida com água destilada quando se observou reação do soro padrão positivo e boa diferenciação com a reação do soro padrão negativo.

Para o WB foi realizada uma eletroforese em gel de poliacrilamida (SDS-PAGE) a 10\% (S AMBROOK; Russell, 2001), a fim de separar os polipeptídeos virais. $\mathrm{O}$ antígeno purificado encontrava-se na concentração de $0,51 \mathrm{mg} / \mathrm{mL}$ e foi diluído (1/2 a 1/256) em tampão de Laemmli preparado de acordo com HeCKerT et al. (1992), aquecido a $100^{\circ} \mathrm{C}$ por 5 minutos e distribuído em dois mini-géis descontínuos de poliacrilamida, em cuba vertical. As condições de corrida dos mini-géis foram corrente de $10 \mathrm{~mA}$ e voltagem de $92 \mathrm{mV}$ por, aproximadamente, uma hora e meia. Para a estimativa do peso molecular das proteínas do antígeno foi utilizado o marcador BenchMark ${ }^{\mathrm{TM}}$ Protein Lader ${ }^{\mathrm{C}}$.

Os polipeptídeos, assim separados, foram transferidos do gel para a membrana de nitrocelulose ${ }^{\mathrm{d}}$ de 0,45 $\mu \mathrm{m}$, pelo método de transferência semi-úmido (KuRIEN; SCOFIELD, 2006), utilizando solução tampão TRIS-glicina (24 mM de TRIS, $192 \mathrm{mM}$ de glicina, metanol 20\%, pH 8,6) (SAMBROOK; RusselL, 2001). A transferência ocorreu por 40 minutos, a $280 \mathrm{~mA}$ e 5 $\mathrm{mV}$. Em seguida as membranas foram embaladas em papel alumínio e conservadas a $-20^{\circ} \mathrm{C}$.

No momento da realização doimmunoblotasmembranas foram descongeladas, cortadas em fitas de 0,6 cm de largura, e bloqueadas com solução de bloqueio (CELER et al., 1998), por uma hora, a temperatura de 25$27^{\circ} \mathrm{C}$, sob leve agitação. Passado o tempo do bloqueio as fitas foram lavadas três vezes, com solução de lavagem, durante cinco minutos. Todos os diluentes, oconjugadoe o substrato foram os mesmos utilizados no dot-blot.

Para realização do teste os soros foram diluídos 1/ 400 , incubados a $37^{\circ} \mathrm{C}$, por uma hora, distribuídos nas fitas que foram incubadas a $25-27^{\circ} \mathrm{C}$, por uma hora sob leve agitação. Em seguida, foram realizadas três lavagens, por cinco minutos, quando o conjugado anti-cabra peroxidase diluído a $1 / 100$ foi distribuído e as fitas incubadas nas condições anteriormente descritas. Após uma hora, as fitas foram lavadas cinco vezes, por cinco minutos, e o substrato TMB adicionado. A reação foi acompanhada e interrompida com água destilada, quando o soro padrão positivo reagiu e apresentou boa diferenciação com a reação do soro padrão negativo.

\footnotetext{
${ }^{\mathrm{b}}$ Antígeno CAEV - ADIG; Biovetech ${ }^{\circledR}$, Brasil.

'Invitrogen, USA.

dMillipore, USA.
} 
Um soro padrão positivo e negativo e oito amostras de soros caprinos naturalmente infectados, identificados como positivos em dois testes de ADIG, consecutivos em intervalos de quatro meses, utilizando okitcomercial ${ }^{\text {, }}$ foram empregados na avaliação do WB.

\section{RESULTADOS E DISCUSSÃO}

\section{Cultivo celular}

As células epiteliais de córnea foram permissíveis à replicação da amostra viral CAEV Cork, apresentando, em torno da $7 \mathbf{z}$ passagem, efeito citopático (ECP) caracterizado pela formação de sincícios, caracterizados por células multinucleadas gigantes, resultante da fusão de células infectadas e nãoinfectadas que foram observadas na segunda semana pós-inoculação (PI), as células continuaram permissíveis pelo menos até 30 a passagem, quando se encerrou a avaliação. Abreu et al. (1998) citaram que o cultivo celular primário que apresenta melhor permissividade à amostra viral CAEV é o de membrana sinovial caprina (MSC), tendo CAEV apresentando replicação satisfatória, tanto em células de baixa passagem (5-a 7 $\stackrel{a}{a})$ como de alta (17aa 18a $)$, produzindo ECP típico. A formação destes sincícios, observados pelas células gigantes multinucleadas, parece ser resultado da interação entre as glicoproteínas do envelope viral e receptores presentes na membrana celular da célula hospedeira (Leroux et al., 1995).

Com base neste comportamento observado, podese concluir que as células epiteliais de córnea apresentam receptores específicos, responsáveis pela adsorção viral, e disponibilidade de fatores celulares para transcrição viral (Huso et al., 1988; Leroux et al., 1995).

\section{Produção e avaliação do antígeno}

$\mathrm{O}$ antígeno produzido apresentou concentração protéica média de $0,48 \mathrm{mg} / \mathrm{mL}$. Quando submetido a SDS-PAGE foram visualizados polipeptídeos virais de diversos pesos moleculares. Por ser um detergente aniônico forte, o SDS quebra as pontes dissulfídricas e dehidrogênio das proteínas, que assumem comportamento de polímeros não estruturados carregados negativamente, permitindo a separação das subunidades polipeptídicas durante corrida eletroforética (WATSOn et al., 2006). SiMARD; BRISCOE (1990a) observaram que concentrações superiores a $0,25 \%$ de SDS, embora permitam uma melhor visualização das subunidades protéicas, promovem perda de reconhecimento de epitópos pelos anticorpos, não sendo recomendada a utilização de concentrações superiores a $0,25 \%$ na preparação de antígenos.

$\mathrm{O}$ dot-blot tem sido considerado um teste atrativo para aplicaçãono diagnóstico derotina delentiviroses, em virtude dos procedimentos permitirem a realização de dezenas de ensaios em membrana de nitrocelulose para detecção de anticorpos com alta sensibilidade e especificidade (PINHEIRO et al., 2001). Além disso, tem se mostrado útil como auxiliar na padronização do WB (ÖZYÖRÜK et al., 2001).

No processo de padronização, a escolha dos diluentes e o estabelecimento da diluição dos reagentes é um ponto crucial. No immunoblot, a detecção dos anticorpos pode ser influenciada tanto pela qualidade quanto pela quantidade do antígeno utilizado. Com a realização do dot-blot foi possível estabelecer a diluição de uso do antígeno $(1 / 4)$, do soro $(1 / 400)$ e do conjugado anti-cabra peroxidase $(1 / 100)$ (Fig. 1). Estas condições, após avaliação nas concentrações imediatamente superior einferior, também se mostraram ideais no WB (dados não demonstrados).
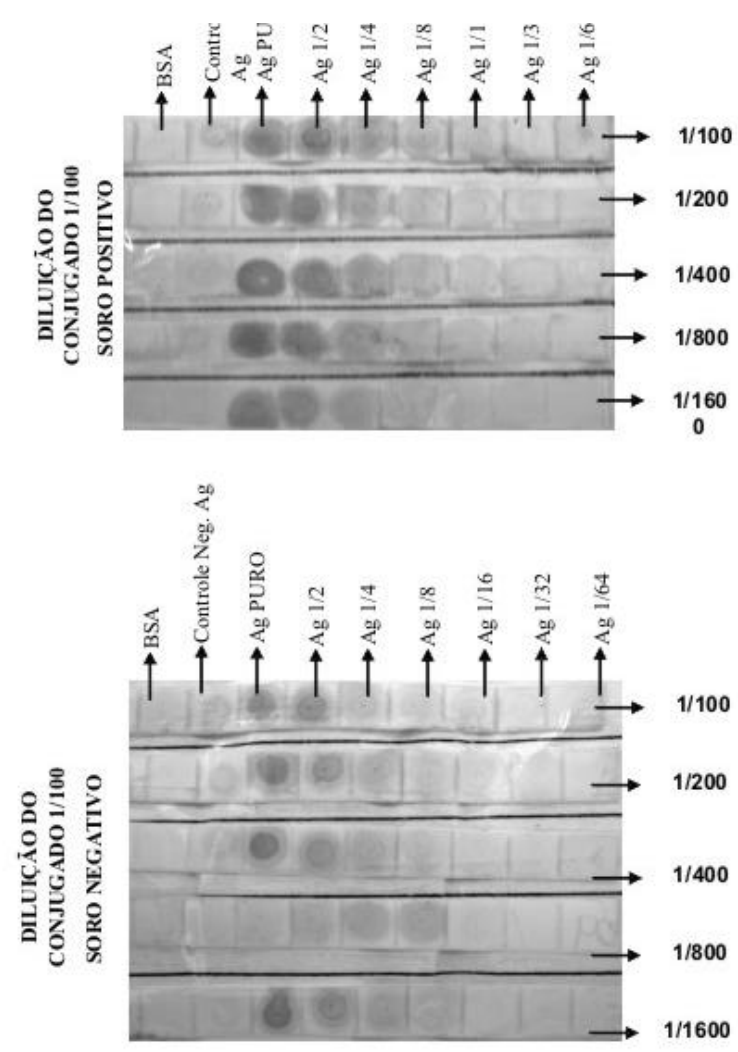

Fig. 1 - Resultado do dot-blot utilizando os soros padrão positivo e negativo diluídos de $1 / 100$ até $1 / 1600$ e conjugado anti-cabra peroxidase $(1 / 100)$.

eAntígeno CAEV - ADIG; Biovetech ${ }^{\circledR}$, Brasil. 
No immunoblot, quando as fitas de nitrocelulose foram incubadas com o soro padrão positivo, observou-se nitidamente reação a cinco proteínas virais, com pesos moleculares de 14-16, 25, 40, 50 e $70 \mathrm{kDa}$ (Fig. 2); nenhuma reação no soro padrão negativo foi evidenciada. Estas proteínas têm sido descritas como reativas em outros trabalhos realizados com soro ovino (ZANONI et al., 1989; Houwers; NAuta, 1989; HeCKert et al., 1992; BRODie et al., 1992; Rosati et al., 1994; VAREAet al., 2001). Adicionalmente, observou-se discreta reação a uma proteína de 14 a 16 kDa no immunoblot com o antígeno diluído 1/2 (Fig. 2). Esta proteína tem sido descrita como sendo de matriz (MA), já detectada em outros estudos realizados utilizando soro ovino (HouWERS; NAUTA, 1989; ZANONI et al., 1989; KAJIKAWA etal., 1990; RosATIet al., 1994; VAREA et al., 2001).

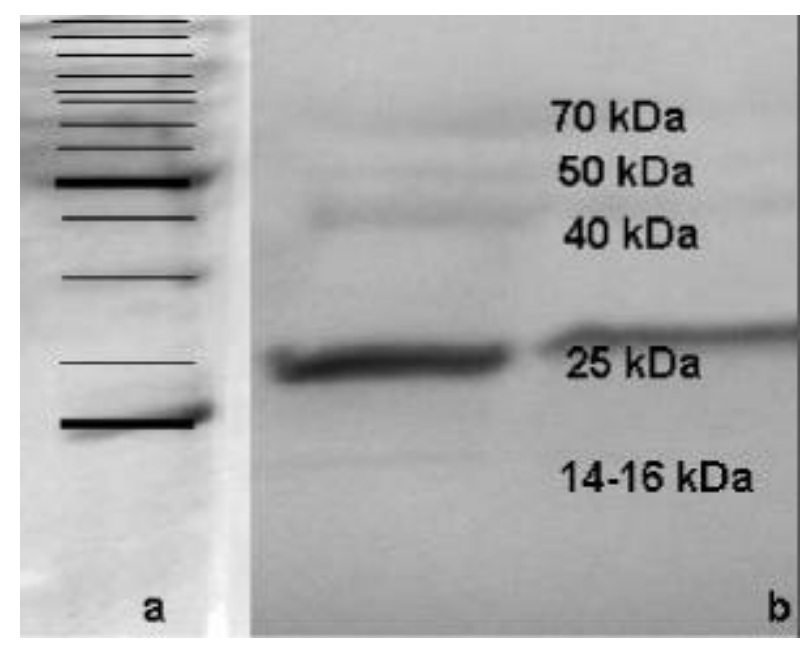

Fig. 2- Resultado do Western Blot. Em a) Gel de poliacrilamida a $10 \%$ corado com Comassie Brilhant BlueR250, mostrando o marcador de peso molecular ladder de 220-14kDa; b) immunoblot com presença de reação positiva a cinco proteínas virais de 70, 50, 40 e $25 \mathrm{kDa}$ ).
A reação do soro padrão positivo mais intensa foi contra um polipeptídeo de aproximadamente 25 kDa, que é identificado como sendo a proteína interna de capsídeo (CA), a mais abundante do vírus eque estimula forte resposta humoral durante a infecção (Houwers; NAutA, 1989; JoAg et al., 1996). Um segundo polipeptíeo, de $40 \mathrm{kDa}$, identificado como uma glicoproteína de transmembrana (gp 40-TM) (Coffin et al.,1996), citada por R osAtiet al. (1995) como maior marcador imunológico nas infecções por $\mathrm{CAEV}$, uma vez que a produção de anticorpos se inicia entre a $20^{\mathrm{a}}$ e $33^{\mathrm{a}}$ semana pós-infecção, tal como acontece nas infecções, em humanos pelo vírus da imunodeficiência humana (HIV), foi observada, também, nos ensaios descritos por ZANONI et al. (1989). A banda protéica de $50 \mathrm{kDa}$, possivelmente um precursor do gene gag Pr50 gag (JoAG et al., 1996), a presentou discreta reação frente ao soro padrão positivo. Foi ainda visualizada reação positiva a uma proteína de $70 \mathrm{kDa}$, descrita como sendo uma glicoproteína de superfície (gp 70), possivelmente, produto de clivagem da glicoproteína de superfície (gp135) (Houwers; Nauta, 1989; HecKert et al.,1992). A intensidade das reações entre o soro padrão e as cinco proteínas foi variável, observando-se maior intensidade de reação com o polipeptídeo de $25 \mathrm{kDa}$, provavelmente pela sua abundância (Fig. 2).

Outros estudos têm demonstrado o reconhecimento de uma proteína de peso molecular de $135 \mathrm{kDa}$ (gp135-SU) (Houwers; NAutA, 1989), não observada neste trabalho. A ausência de reação a esta proteína pode ser devido à redução na reatividade das proteínas glicosiladas nas condições do immunoblot (Houwers; NAuta, 1989) ou, ainda, uma conseqüência do processo de purificação do antígeno, pois as partículas virais podem perder o antígeno de envelope, principalmente quando se utiliza gradiente contínuo de sacarose (KAJIKAWA et al.,1990; B RODIE et al., 1992).

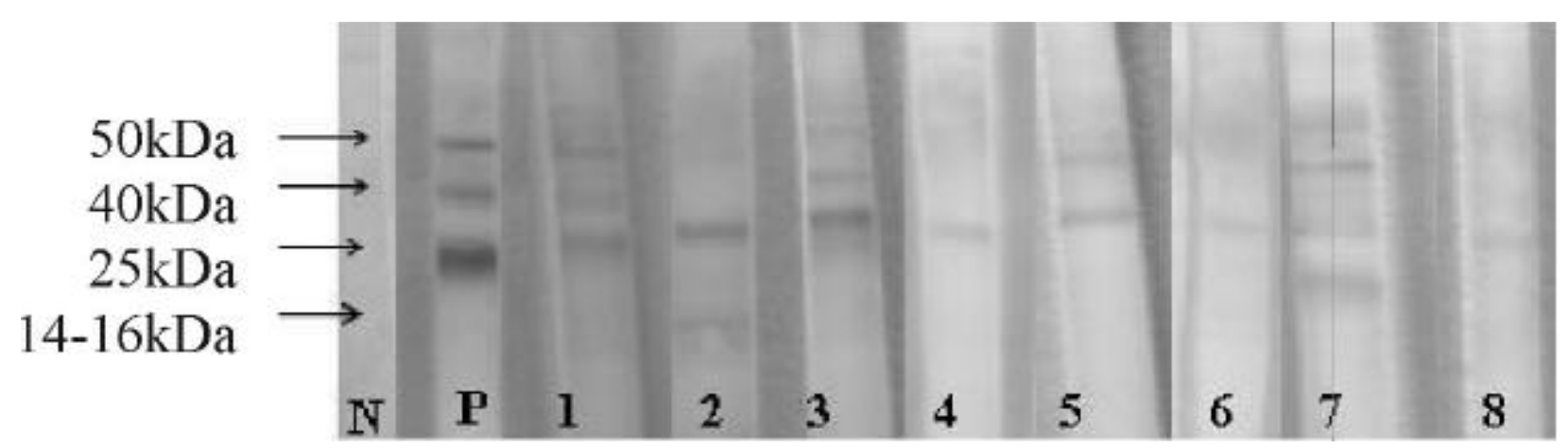

Fig. 3 - Resultado do immunoblot realizado com oito amostras de soro caprino, positivos para lentivírus de pequenos ruminantes (SRLV) na imunodifusão em gel de agar (ADIG). Em N) Soro padrão negativo P) Soro padrão positivo; 1 a 8) Amostras de soro caprino positivos na ADIG. 
Ao se realizar o immunoblot em oito amostras de soro caprino, de campo, positivo na ADIG, observouseque todos os animais apresentaram reação positiva a pelo menos uma proteína. Dois animais apresentaram reação positiva à p16 ou p14, e dois a gp 50 , estas reações ocorreram com baixa intensidade. Ao polipeptídeo de $25 \mathrm{kDa}$ todos os animais reagiram com intensidade variável. Reação positiva a gp 40 foi observada em quatro animais (animais 1,3,5e7), com intensidade de reação discreta em três deles (Fig. 3). Os soros padrão positivo e os soros de campo, neste ensaio, não reconheceram a proteína de $70 \mathrm{kDa}$. A diferença nos padrões de reconhecimento das proteínas virais pode possivelmente também ter relação com fatores não passíveis de avaliação neste estudo, devido ao número de amostras testadas. É necessário investigar sua relação com a forma clínica, tempo de infecção, sexo e origem dos animais, dentre outros.

\section{CONCLUSÃO}

Pelo exposto pode-se concluir que o western blotéuma técnica que tem potencial emprego no diagnóstico de SRLV, precisando ser mais amplamente avaliada. O protocolo empregado para purificação de antígenos foi satisfatório, rendendo uma concentração proteíca antigênica igual ou inferior à obtida em outros estudos, onde se trabalharam com outros tipos de células primárias, taiscomoascélulas demembrana desinovialcaprina (MSC) (CASTRO, 1998; PINHEIRO, 2001; ARAGÃo, 2007), poréménecessárioqueestudos deviabilidadedeseu usoem outros ensaios imunoenzimáticos sejam realizados.

\section{AGRADECIMENTOS}

Ao Conselho Nacional de Desenvolvimento Científico e Tecnológico (CNPq), pela bolsa de doutorado edeDTI. À Fundaçãode Amparoà Ciênciae Tecnologia doEstado de Pernambuco (FACEPE) eà Financiadora de Estudos e Projetos (FINEP), pelo apoio financeiro.

\section{REFERÊNCIAS}

ABREU, S.R.O.; CASTRO, R.S.; NASCIMENTO, S.A.; SOUZA, M.G. Produção de antígeno nucleoproteíco do vírus da Artrite-Encefalite Caprina e comparação com o do vírus Maedi-Visna para utilização em teste de imunodifusão em agar gel. Pesquisa Veterinária Brasileira, v.18, n.2, p.57-60, 1998.

ARAGÃO, M.A.C. Desenvolvimento e padronização do DotElisa para o diagnóstico sorológico da Maedi-Visna. 2007. 94p. Dissertação (Mestrado) - Universidade Estadual do Ceará, Fortaleza, 2007. (disponível na internet).
ARCHAMBAULT, D.; EAST, N.; PERK, K.; DAHLBERG, J.E. Development of an enzyme-linked immunosorbent assay for caprine arthritisencephalitis virus. Journal of Clinical Microbiology, v. 26, n.5, p.971-975, 1988.

BRASIL. Ministério da Agricultura Pecuária e Abastecimento. Portaria $\mathrm{n}^{\mathrm{o}} 103$, de 07 de dezembro de 2004. Dispo-nível em: <http:/ / extranet.agricultura. gov.br/ sislegis>. Acesso em 4 abr. 2006.

\section{BRODIE, S.J.; PEARSON, L.D.; SNOWDER, G.D.; DE} MARTINI, J.C. Host-virus interaction as defined by amplification of viral DNA and serology in lentivirusinefected sheep. Archives of Virology, v.130, p.413-428, 1992.

CASTRO, R.S. Lentivírus de pequenos ruminantes: ensaios imunoenzimáticos, perfil sorológico e inferências filogenéticas. 1998. 132 f. Tese (Doutorado em Ciência Veterinária) - Escola de Veterinária, Universidade Federal de Minas Gerais, Belo Horizonte, 1998.

CALLADO, A.K.C. Caracterização preliminar da infecção de células de membrana sinovial por amostras brasileiras de lentivírus de pequenos ruminantes. 1999. 50f. Dissertação (Mestrado em Produção e Reprodução de Pequenos Ruminantes) - Universidade Estadual do Ceará, Fortaleza, 1999.

CALLADO, A.K.C.; CASTRO, R.S.; TEIXEIRA, M.F.S. Lentivírus de Pequenos Ruminantes (AEV e MaediVisna): revisão e perspectivas. Pesquisa Veterinária Brasileira, v.21, n.3, p.87-97, 2001.

CELER JUNIOR, V.; CELER, V.; NEMCOVA, H.R.; ZANONI, R.G.; PETERHANS, E. Serologic diagnosis of ovine lentiviruses by whole virus ELISA and AGID test. Journal of Veterinary Medicine Series B, v.45, p.183186, 1998.

CELER JUNIOR, V.; CELER, V. Detection of antibodies to ovine lentivirus using recombinant capsid and transmembrane proteins. Journal of Veterinary Medicine Series B, v.48, p.89-95, 2001.

COFFIN, J.M. Retroviridae: The virus and their replication. In: FIELDS, B.N.; KNIPE, D.M.; HOWLEY, P.M.; CHANOCK, R.M.; MELNICK, J.L.; MONATH, T.P.; ROIZMAN, B.; STRAUS, S.E. (Ed.). Fields firology. Philadelphia: Lippincott-Raven, 1996. p.1767-1847.

HECKERT, R.A.; MCNAB, W.B.; RICHARDSON, S.M.; BISCOE, M.R. Evaluation of an enzyme-linked immunosorbent assay for the detection of antibodies to caprine arthritis-encephalitis virus in goat serum. Canadian Journal Veterinary Research, v.56, p.237-241, 1992.

HOUWERS, D.J.; GIELKENS, A.L.J.; JAN SCHAAKE JUNIOR, J. An indirect enzyme-linked immunosorbent assay (ELISA) for the detection of antibodies to MAEDIVISNA virus. Veterinary Microbiology, v.7, p.209-219, 1982. 
HOUWERS, D.J.; NAUTA, I.M. Immunoblot analysis of the antibody response to ovine lentivirus infections. Veterinary Microbiology, v.19, p.127-139, 1989.

HUSO, D.L.; NARAYAN, O.; HART, G.W. Sialic acids on the surface of caprine arthritis-encephalitis virus define the biological properties of the virus. Journal of Virology, v.62, p.1974-1980, 1988.

JOAG, S.V.; STEPHENS, E.B.; NARAYAN, O. Lentiviruses. In: FIELDS, B.N.; KNIPE, D.M.; HOWLEY, P.M.; CHANOCK, R.M.; MELNICK, J.L.; MONATH, T.P.; ROIZMAN, B.; STRAUS, S.E. (Ed.). Fields virology. Philadelphia: Lippincott-Raven, 1996. p.1777-1996.

KAJIKAWA, O.; LAIRMORE, M.D.; DEMARTINI, J.C. Analysis of antibody responses to phenotypically distinct lentiviruses. Journal of Clinical Microbiology, v.28, p.764-770, 1990.

KURIEN, B.T.; SCOFIELD, H.R. Western blotting. Methods, v.38, p.283-293, 2006.

LEROUX, C.; CORDIER, G.; MERCIER, I.; CHASTANG, J.; LYON, M.; QUÉRAT, G.; GREENLAND, T.; VIGNE, R.; MORNEX, J.F. Ovine aortic smooth muscle cells allow the replication of visna-maedi virus in vitro. Archives of Virology, v.140, p.1-11, 1995.

NARAYAN, O.; CLEMENTES, J.E.; STRANDBERG, J.D.; CORK, L.C.; GRIFFIN, D.E. Biological characterization of the virus causing leukoencephalitis and arthritis in goats. Journal of General Virology, v.59, p.69-79, 1980.

ÖZYÖRÜK, F.; CHEEVERS, W.P.; HULLINGER, G.A.; MCGUIRE, T.C.; HUTTON, M.; KNOWLES, D.P. Monoclonal antibodies to conformational epitopes of the surface glycoprotein of caprine arthritisencephalitis virus: potential application to competitive-encephalitis enzyme-linked immunosorbent assay for detecting antibodies in goat sera. Clinical and Diagnostic Laboratory Immunology, v.8, p. 44-51, 2001.

PINHEIRO, R.R. Virus da Artrite Encefalite Caprina: desenvolvimento e padronização de ensaios imunoenzimáticos (ELISA e Dot-Blot) e estudo epidemiológico no Estado do Ceará. 2001. 115p. Tese (Doutorado) - Universidade Federal de Minas Gerais, Belo Horizonte, 2001.

PINHEIRO, R.R.; GOUVEIA, A.M.G.; OLORTEGUI, C.C.; ANDRIOLI, L.; ARAÚJO, S.C. Dot-Blot: Alternativa para o diagnóstico da artrite-encefalite caprina (AEC). Sobral: CNPC, 2001. 4p. (Comunicado Técnico n.57).

ROSATI, S.; KWANG, J.; TOLARI, F.; KEEN, J.E. A comparasion of whole virus and recombinant transmembrane ELISA and immunodiffusion for detection of ovine lentivirus antibodies in Italian sheep flocks. Veterinary Research Communications, v.18, p.73-80, 1994.

ROSATI, S.; PITTAU, M.; TOLARI, F.; ERRE, G.; KWANG, J. Genetic and antigenic characterization of CAEV (caprine arthritis-encephalitis virus) recombinant transmembrane protein. Veterinay Microbiology, v.45, p.363-370, 1995.

SAMBROOK, J.; RUSSELL, D.W. Molecular cloning: a labotatory manual. 3.ed. Woodbury: Cold Spring Harbor Laboratory Press, 2001. v.3.

SEDMAK, J.J.; GROSSBERG, S.E. A rapid, sensitive and versatile assay for protein using coomassie brilliant blue G250. Analitical Biochemistry, v.79, p.544552, 1977.

SHAH, C.; BÖNI, J.; HUDER, J.B.; VOGT, H.R.; MÜHLHER, J.; ZANONI, R.; MISEREZ, R.; LUTZ, H.; SCHÜPBACH, J. Phylogenetic analysis and reclassification of caprine and ovine lentiviruses based on 104 new isolates: evidence for regular sheep-to-goat transmission and worldwide propagation through livestock trade. Virology, v.319, p.12-26, 2004.

SIMARD, C.L.; BRISCOE, M.R. An enzyme-linked immunosorbent assay for detection of antibodies to maedi-visna virus in sheep i. a simple technique for production of antigen using sodium dodecyl sulfate treatment. Canadian Journal of Veterinary Research, v.54, p.446-450, 1990a.

SIMARD, C.L.; BRISCOE, M.R. An enzyme-linked immunosorbent assay for detection of antibodies to maedi-visna virus in sheep ii. comparison to conventional agar gel immunodiffusion test. Canadian Journal of Veterinary Research, v.54, p.451456, 1990b.

SIMARD, C.L.; KIBENGE, M.T.; SINGH, P.; DIXON, P. Simple and rapid method for production of wholevirus antigen for serodiagnosis of caprine arthritisencephalitis virus by enzyme-linked immunosorbent assay. Clinical and Diagnostic Laboratory Immunology, v.8, p.352-356, 2001.

VAREA, R.; MONLEÓN, E.; PACHECO, C.; LUJÁN, L.; BOLEA, R.; VARGAS, M.A.; VAN EYNDE, G.; SAMAN, E.; DICKSON, L.; HARKISS, G. AMORENA, B.; BADIOLA, J.J. Early detection of maedi-visna (ovine progressive pneumonia) virus soroconversion in field sheep samples. Journal of Veterinary Diagnostic Investigation, v.13, p.301-307, 2001.

WATSON, J.D.; BAKER, T.A.; BELL, S.P. Biologia Molecular do Gene. 5.ed. Porto Alegre: Artmed, 2006. $760 \mathrm{p}$ 
ZANONI, R.; KRIEG, A.; PETERHANs, E. Detection of antibodies to caprine arthritis-encephalitis virus by protein $\mathrm{G}$ enzyme-linked immunosorbent assay and immunoblotting. Journal of Clinical Microbiology, v.27, p.580-582, 1989.

ZANONI, R.G.; VOGT, H.R.; POHL, B.; BÖTTCHER, J.; BOMMELI, W.; PETERHANS, E. An ELISA based on whole virus for the detection of antibodies to smallruminant lentiviruses. Zentralblatt für Veterinärmededezin [B], v.41, p.662-669, 1994.

Recebido em 11/9/07

Aceito em 12/8/08 